\title{
On the Rate of Convergence of P-Iteration, SP-Iteration, and D-Iteration Methods for Continuous Nondecreasing Functions on Closed Intervals
}

\author{
Jukkrit Daengsaen $^{1}$ and Anchalee Khemphet $\mathbb{D}^{2}$ \\ ${ }^{1}$ Department of Mathematics, Faculty of Science, Chiang Mai University, Chiang Mai 50200, Thailand \\ ${ }^{2}$ Center of Excellence in Mathematics and Applied Mathematics, Department of Mathematics, Faculty of Science, \\ Chiang Mai University, Chiang Mai 50200, Thailand
}

Correspondence should be addressed to Anchalee Khemphet; anchalee.k@cmu.ac.th

Received 2 March 2018; Revised 24 May 2018; Accepted 29 May 2018; Published 2 July 2018

Academic Editor: Simeon Reich

Copyright (C) 2018 Jukkrit Daengsaen and Anchalee Khemphet. This is an open access article distributed under the Creative Commons Attribution License, which permits unrestricted use, distribution, and reproduction in any medium, provided the original work is properly cited.

\begin{abstract}
We introduce a new iterative method called D-iteration to approximate a fixed point of continuous nondecreasing functions on arbitrary closed intervals. The purpose is to improve the rate of convergence compared to previous work. Specifically, our main result shows that D-iteration converges faster than P-iteration and SP-iteration to the fixed point. Consequently, we have that Diteration converges faster than the others under the same computational cost. Moreover, the analogue of their convergence theorem holds for D-iteration.
\end{abstract}

\section{Introduction}

Let $E \subseteq \mathbb{R}$ be a closed interval. Define $f: E \longrightarrow E$ to be a continuous mapping. A point $p \in E$ is said to be a fixed point of $f$ if $f(p)=p$. The set of all fixed points of $f$ is denoted by $F(f)$. It is a well-known fact that $f$ has a fixed point if the interval $E$ is bounded. A popular way of finding a fixed point of $f$ is an iterative method.

In 1953, Mann [1] proposed an iteration, Mann iteration, defined by $u_{1} \in E$ and

$$
u_{n+1}=\left(1-\alpha_{n}\right) u_{n}+\alpha_{n} f\left(u_{n}\right)
$$

where $\alpha_{n} \in[0,1]$ and $n \in \mathbb{N}$. Then, a two-step iteration, Ishikawa iteration [2], was introduced in 1974 and defined by $p_{1} \in E$ and

$$
\begin{aligned}
q_{n} & =\left(1-\beta_{n}\right) p_{n}+\beta_{n} f\left(p_{n}\right) \\
p_{n+1} & =\left(1-\alpha_{n}\right) p_{n}+\alpha_{n} f\left(q_{n}\right)
\end{aligned}
$$

$\alpha_{n}, \beta_{n} \in[0,1]$ and $n \in \mathbb{N}$. Two years later, Rhoades [3] showed that Mann and Ishikawa iterations converge for the class of continuous nondecreasing functions on a unit closed interval. Next, Borwein and Borwein [4] proved that Mann iteration converges for the class of continuous mappings on a bounded closed interval in 1991. In 2000, Noor [5] introduced a new three-step iterative method, Noor iteration, defined by $v_{1} \in E$ and

$$
\begin{gathered}
r_{n}=\left(1-\gamma_{n}\right) v_{n}+\gamma_{n} f\left(v_{n}\right) \\
o_{n}=\left(1-\beta_{n}\right) v_{n}+\beta_{n} f\left(r_{n}\right) \\
v_{n+1}=\left(1-\alpha_{n}\right) v_{n}+\alpha_{n} f\left(o_{n}\right)
\end{gathered}
$$

where $\alpha_{n}, \beta_{n}, \gamma_{n} \in[0,1]$ and $n \in \mathbb{N}$. Then, Qing and Qihou [6] extended the results of Rhoades [3] and Borwein and Borwein [4] to the class of continuous functions on an arbitrary interval in 2006. On top of that, a necessary and sufficient condition for the convergence of Ishikawa iteration on an arbitrary interval was provided. 
In 2011, Phuengrattana and Suantai [7] introduced an iteration, called SP-iteration, defined by $h_{1} \in E$ and

$$
\begin{aligned}
b_{n} & =\left(1-\gamma_{n}\right) h_{n}+\gamma_{n} f\left(h_{n}\right) \\
l_{n} & =\left(1-\beta_{n}\right) b_{n}+\beta_{n} f\left(b_{n}\right) \\
h_{n+1} & =\left(1-\alpha_{n}\right) l_{n}+\alpha_{n} f\left(l_{n}\right)
\end{aligned}
$$

where $\alpha_{n}, \beta_{n}, \gamma_{n} \in[0,1]$ and $n \in \mathbb{N}$. In addition, the convergence of this three-step iteration holds for continuous functions on an arbitrary interval. Moreover, they showed that SP-iteration converges faster than Mann, Ishikawa, and Noor iterations for the class of continuous nondecreasing functions.

Two years later, Kosol [8] studied the convergence of S-iteration [9] for the class of continuous nondecreasing functions on a closed interval. S-iteration was first introduced by Agarwal et al. [9] and defined by $d_{1} \in E$ and

$$
\begin{aligned}
e_{n} & =\left(1-\beta_{n}\right) d_{n}+\beta_{n} f\left(d_{n}\right) \\
d_{n+1} & =\left(1-\alpha_{n}\right) f\left(d_{n}\right)+\alpha_{n} f\left(e_{n}\right)
\end{aligned}
$$

where $\alpha_{n}, \beta_{n} \in[0,1]$ and $n \in \mathbb{N}$. In 2015, Sainuan [10] constructed a new iteration, called P-iteration, and showed that this iteration converges faster than S-iteration for the class of continuous nondecreasing functions. P-iteration is defined by $w_{1} \in E$ and

$$
\begin{aligned}
t_{n} & =\left(1-\gamma_{n}\right) w_{n}+\gamma_{n} f\left(w_{n}\right) \\
s_{n} & =\left(1-\beta_{n}\right) t_{n}+\beta_{n} f\left(t_{n}\right) \\
w_{n+1} & =\left(1-\alpha_{n}\right) f\left(t_{n}\right)+\alpha_{n} f\left(s_{n}\right)
\end{aligned}
$$

where $\alpha_{n}, \beta_{n}, \gamma_{n} \in[0,1]$ and $n \in \mathbb{N}$.

Motivated by the above results, we define $\mathrm{D}$-iteration by $x_{1} \in E$ and

$$
\begin{aligned}
z_{n} & =\left(1-\gamma_{n}\right) x_{n}+\gamma_{n} f\left(x_{n}\right) \\
y_{n} & =\left(1-\beta_{n}\right) f\left(x_{n}\right)+\beta_{n} f\left(z_{n}\right) \\
x_{n+1} & =\left(1-\alpha_{n}\right) f\left(z_{n}\right)+\alpha_{n} f\left(y_{n}\right)
\end{aligned}
$$

where $\alpha_{n}, \beta_{n}, \gamma_{n} \in[0,1]$ and $n \in \mathbb{N}$.

In this work, we give a necessary and sufficient condition for the convergence of D-iteration. Then, we show that D-iteration converges faster than other iterations for the class of continuous nondecreasing functions. Also, numerical examples are provided to support our result.

\section{Convergence Theorem}

In this section, we provide the convergence theorem of Diteration for the class of continuous nondecreasing functions on an arbitrary closed interval. First, we begin with the following lemma.

Lemma 1. Let $f: E \longrightarrow E$ be a continuous nondecreasing function, and let $\left(x_{n}\right)$ be a sequence defined by (7). (i) If $f\left(x_{1}\right)<x_{1}$, then $f\left(x_{n}\right) \leq x_{n}$ for all $n \in \mathbb{N}$ and $\left(x_{n}\right)$ is nonincreasing.

(ii) If $f\left(x_{1}\right)>x_{1}$, then $f\left(x_{n}\right) \geq x_{n}$ for all $n \in \mathbb{N}$ and $\left(x_{n}\right)$ is nondecreasing.

Proof. (i) Assume that $f\left(x_{1}\right)<x_{1}$. We will show that $f\left(x_{n}\right) \leq$ $x_{n}$ for all $n \in \mathbb{N}$ by induction on $n$. Clearly, this is true for $n=1$. Assume that $f\left(x_{k}\right) \leq x_{k}$ for some $k \geq 1$. From (7), we have that $f\left(x_{k}\right) \leq z_{k} \leq x_{k}$. Since $f$ is nondecreasing, $f\left(z_{k}\right) \leq f\left(x_{k}\right) \leq z_{k}$. By the definition of $y_{k}, f\left(z_{k}\right) \leq y_{k} \leq z_{k}$. Then, $f\left(y_{k}\right) \leq f\left(z_{k}\right) \leq y_{k}$ since $f$ is nondecreasing. Similarly, $f\left(y_{k}\right) \leq x_{k+1} \leq y_{k}$, and finally, we obtain that $f\left(x_{k+1}\right) \leq$ $f\left(y_{k}\right) \leq x_{k+1}$. Thus, $f\left(x_{n}\right) \leq x_{n}$ for all $n \in \mathbb{N}$. Moreover, by the proof above, we have that $x_{k+1} \leq x_{k}$ for all $k \in \mathbb{N}$. Therefore, $\left(x_{n}\right)$ is nonincreasing.

(ii) The proof can be done similarly as in (i).

Theorem 2. Let $f: E \longrightarrow E$ be a continuous nondecreasing function, and let $\left(x_{n}\right)$ be a sequence defined by (7), where $\lim _{n \rightarrow \infty} \alpha_{n}=0$ and $\lim _{n \rightarrow \infty} \gamma_{n}=0$. Then, $\left(x_{n}\right)$ is bounded if and only if it converges to a fixed point of $f$.

Proof. Assume that $\left(x_{n}\right)$ is bounded. First, we will show that it is convergent. If $f\left(x_{1}\right)=x_{1}$, by (7), we obtain that $x_{n}=x_{1}$ for all $n \in \mathbb{N}$. Therefore, $\left(x_{n}\right)$ is convergent. Suppose that $f\left(x_{1}\right) \neq$ $x_{1}$. From Lemma 1 , we have that $\left(x_{n}\right)$ is either nonincreasing or nondecreasing. Since $\left(x_{n}\right)$ is bounded, it follows that $\left(x_{n}\right)$ is convergent. Assume that $\left(x_{n}\right)$ converges to $p$ for some $p \in$ $E$. Next, we will show that $p$ is a fixed point of $f$. Since $f$ is continuous and $\left(x_{n}\right)$ is bounded, we have that $\left(f\left(x_{n}\right)\right)$ is bounded and so are $\left(z_{n}\right),\left(f\left(z_{n}\right)\right),\left(y_{n}\right)$ and $\left(f\left(y_{n}\right)\right)$. Note that $z_{n}=x_{n}+\gamma_{n}\left(f\left(x_{n}\right)-x_{n}\right) \longrightarrow p$ since $\gamma_{n} \longrightarrow 0$.

From (7), we obtain that

$$
\begin{aligned}
x_{n+1}-x_{n}= & \left(f\left(z_{n}\right)-z_{n}\right)+\gamma_{n}\left(f\left(x_{n}\right)-x_{n}\right) \\
& +\alpha_{n}\left(f\left(y_{n}\right)-f\left(z_{n}\right)\right)
\end{aligned}
$$

Since $\alpha_{n} \longrightarrow 0, \gamma_{n} \longrightarrow 0$, and $f$ is continuous, we obtain that

$$
\begin{aligned}
0 & =p-p=\lim _{n \longrightarrow \infty}\left(x_{n+1}-x_{n}\right)=\lim _{n \longrightarrow \infty} f\left(z_{n}\right)-z_{n} \\
& =f(p)-p .
\end{aligned}
$$

Therefore, $f(p)=p$.

Conversely, if $\left(x_{n}\right)$ is convergent, then it is obvious that $\left(x_{n}\right)$ is bounded.

Consequently, one can see from Theorem 2 that Diteration always converges to a fixed point of $f$, where $f$ is a continuous nondecreasing function defined on a bounded closed interval.

Corollary 3. Let $f:[a, b] \longrightarrow[a, b]$ be a continuous nondecreasing function, and let $\left(x_{n}\right)$ be a sequence defined by (7), where $\lim _{n \rightarrow \infty} \alpha_{n}=0$ and $\lim _{n \rightarrow \infty} \gamma_{n}=0$. Then, $\left(x_{n}\right)$ converges to a fixed point of $f$. 


\section{Rate of Convergence}

To prove our main theorem, we first define how to compare the rate of convergence between two iteration methods and then give some useful lemmas to accomplish our result.

Definition 4. Let $f: E \longrightarrow E$ be a continuous function, and let $\left(x_{n}\right)$ and $\left(w_{n}\right)$ be two iterations which converge to the same point $p \in E$. Then $\left(x_{n}\right)$ is said to converge faster than $\left(w_{n}\right)$ if $\left|x_{n}-p\right| \leq\left|w_{n}-p\right|$ for all $n \in \mathbb{N}$.

Lemma 5. Let $f: E \longrightarrow E$ be a continuous nondecreasing function, and let $\left(x_{n}\right)$ be a sequence defined by (7). Assume that there exists a point $p \in F(f)$.

(i) If $x_{1}>p$, then $x_{n} \geq p$ for all $n \in \mathbb{N}$.

(ii) If $x_{1}<p$, then $x_{n} \leq p$ for all $n \in \mathbb{N}$.

Proof. (i) Let $x_{1}>p$. We will show by induction that $x_{n} \geq p$ for all $n \in \mathbb{N}$. It is clear that this is true for the case $n=1$. Assume that $x_{k} \geq p$ for some $k \geq 1$. Since $f$ is nondecreasing, $f\left(x_{k}\right) \geq p$. By the definition of $z_{k}$, we have that

$$
z_{k}=\left(1-\gamma_{k}\right) x_{k}+\gamma_{k} f\left(x_{k}\right) \geq p .
$$

Thus, $f\left(z_{k}\right) \geq p$. Similarly,

$$
y_{k}=\left(1-\beta_{k}\right) f\left(x_{k}\right)+\beta_{k} f\left(z_{k}\right) \geq p .
$$

Therefore, $f\left(y_{k}\right) \geq p$. From (7), we obtain that

$$
x_{k+1}=\left(1-\alpha_{k}\right) f\left(z_{k}\right)+\alpha_{k} f\left(y_{k}\right) \geq p .
$$

Hence, $x_{n} \geq p$ for all $n \in \mathbb{N}$.

(ii) By using the same proof as in (i), we are done.

Lemma 6. Let $f: E \longrightarrow E$ be a continuous nondecreasing function, and let $\left(h_{n}\right),\left(w_{n}\right)$, and $\left(x_{n}\right)$ be sequences defined by (4), (6), and (7), respectively, where $h_{1}=w_{1}=x_{1} \in E$.

(i) If $f\left(x_{1}\right)<x_{1}$, then $x_{n} \leq w_{n} \leq h_{n}$ for all $n \in \mathbb{N}$.

(ii) If $f\left(x_{1}\right)>x_{1}$, then $x_{n} \geq w_{n} \geq h_{n}$ for all $n \in \mathbb{N}$.

Proof. (i) Let $f\left(x_{1}\right)<x_{1}$. First, we show that $x_{n} \leq w_{n}$ for all $n \in \mathbb{N}$ by induction. It is obvious that this inequality holds for the case $n=1$. Assume that $x_{k} \leq w_{k}$ for some $k \geq 1$. Since $f$ is nondecreasing, $f\left(x_{k}\right) \leq f\left(w_{k}\right)$. Since $f\left(x_{1}\right)<x_{1}$, by Lemma 1(i), $f\left(x_{k}\right) \leq x_{k}$. It follows that $f\left(x_{k}\right) \leq z_{k}$ by the definition of $z_{k}$. From iterations (6) and (7), we have that

$$
\begin{aligned}
z_{k}-t_{k} & =\left(1-\gamma_{k}\right)\left(x_{k}-w_{k}\right)+\gamma_{k}\left(f\left(x_{k}\right)-f\left(w_{k}\right)\right) \\
& \leq 0 .
\end{aligned}
$$

Thus, $z_{k} \leq t_{k}$. Therefore, $f\left(z_{k}\right) \leq f\left(t_{k}\right)$. Then,

$$
\begin{aligned}
y_{k}-s_{k}= & \left(1-\beta_{k}\right)\left(f\left(x_{k}\right)-t_{k}\right) \\
& +\beta_{k}\left(f\left(z_{k}\right)-f\left(t_{k}\right)\right) \leq 0 .
\end{aligned}
$$

That is, $y_{k} \leq s_{k}$ which implies $f\left(y_{k}\right) \leq f\left(s_{k}\right)$. Consider

$$
\begin{aligned}
x_{k+1}-w_{k+1}= & \left(1-\alpha_{k}\right)\left(f\left(z_{k}\right)-f\left(t_{k}\right)\right) \\
& +\alpha_{k}\left(f\left(y_{k}\right)-f\left(s_{k}\right)\right) \leq 0 .
\end{aligned}
$$

We obtain that $x_{k+1} \leq w_{k+1}$. By induction, we can conclude that $x_{n} \leq w_{n}$ for all $n \in \mathbb{N}$. Next, we show that $w_{n} \leq h_{n}$ for all $n \in \mathbb{N}$ by induction. It is clear that this is true for the case $n=$ 1 . Assume that $w_{k} \leq h_{k}$ for some $k \geq 1$. Then $f\left(w_{k}\right) \leq f\left(h_{k}\right)$. Since $f\left(h_{1}\right)<h_{1}$, we have that $f\left(h_{k}\right) \leq h_{k}$ (see [7] Lemma 3.2 (vii)). From (4), $f\left(h_{k}\right) \leq b_{k} \leq h_{k}$. Since $f$ is nondecreasing, $f\left(b_{k}\right) \leq f\left(h_{k}\right) \leq b_{k}$. By the definition of $l_{k}, f\left(b_{k}\right) \leq l_{k}$. By (4) and (6), we have that

$$
\begin{aligned}
t_{k}-b_{k} & =\left(1-\gamma_{k}\right)\left(w_{k}-h_{k}\right)+\gamma_{k}\left(f\left(w_{k}\right)-f\left(h_{k}\right)\right) \\
& \leq 0 .
\end{aligned}
$$

Thus, $t_{k} \leq b_{k}$. Since $f$ is nondecreasing, $f\left(t_{k}\right) \leq f\left(b_{k}\right) \leq l_{k}$. Then,

$$
s_{k}-l_{k}=\left(1-\beta_{k}\right)\left(t_{k}-b_{k}\right)+\beta_{k}\left(f\left(t_{k}\right)-f\left(b_{k}\right)\right) \leq 0 .
$$

That is, $s_{k} \leq l_{k}$. Therefore, $f\left(s_{k}\right) \leq f\left(l_{k}\right)$. Consider

$$
\begin{aligned}
w_{k+1}-h_{k+1}= & \left(1-\alpha_{k}\right)\left(f\left(t_{k}\right)-l_{k}\right) \\
& +\alpha_{k}\left(f\left(s_{k}\right)-f\left(l_{k}\right)\right) \leq 0 .
\end{aligned}
$$

We have that $w_{k+1} \leq h_{k+1}$. By induction, we can conclude that $w_{n} \leq h_{n}$ for all $n \in \mathbb{N}$.

(ii) By using similar arguments as in (i) together with Lemma 1(ii) and Lemma 3.2 (viii) in [7], we are done.

Proposition 7. Let $f: E \longrightarrow E$ be a continuous nondecreasing function such that $F(f)$ is nonempty and bounded. If $x_{1}>$ $\sup F(f)$ and $f\left(x_{1}\right)>x_{1}$, then $\left(x_{n}\right)$ defined by (7) does not converge to a fixed point of $f$.

Proof. Assume that $x_{1}>\sup F(f)$ and $f\left(x_{1}\right)>x_{1}$. Then, by Lemma 1(ii), $\left(x_{n}\right)$ is nondecreasing. Since $x_{1}>\sup F(f)$, it follows that $\left(x_{n}\right)$ does not converge to a fixed point of $f$.

Proposition 8. Let $f: E \longrightarrow$ E be a continuous nondecreasing function such that $F(f)$ is nonempty and bounded. If $x_{1}<$ $\inf F(f)$ and $f\left(x_{1}\right)<x_{1}$, then $\left(x_{n}\right)$ defined by (7) does not converge to a fixed point of $f$.

Proof. Assume that $x_{1}<\inf F(f)$ and $f\left(x_{1}\right)<x_{1}$. Then, by Lemma 1(i), $\left(x_{n}\right)$ is nonincreasing. Since $x_{1}<\inf F(f),\left(x_{n}\right)$ does not converge to a fixed point of $f$.

In 2011, Phuengrattana and Suantai [7] compared the rate of convergence of Mann, Ishikawa, and Noor iterations with SP-iteration. Four years later, Sainuan [10] studied the rate of convergence between P-iteration and S-iteration. Their results are concluded as the following.

Theorem 9 (see $[7,10]$ ). Let $f: E \longrightarrow E$ be a continuous nondecreasing function such that $F(f)$ is nonempty and bounded. For the same initial point and $p \in F(f)$, the following are satisfied.

(i) Ishikawa iteration converges to $p$ if and only if Mann iteration converges to $p$. Moreover, Ishikawa iteration converges faster than Mann iteration. 
(ii) Noor iteration converges to $p$ if and only if Ishikawa iteration converges to $p$. Moreover, Noor iteration converges faster than Ishikawa iteration.

(iii) SP-iteration converges to $p$ if and only if Noor iteration converges to $p$. Moreover, SP-iteration converges faster than Noor iteration.

(iv) If S-iteration converges to $p$, then P-iteration converges to $p$. Moreover, P-iteration converges faster than $S$ iteration.

Remark 10. From Theorem 9, one can conclude that SPiteration is better than Noor, Ishikawa, and Mann iterations. However, one can come to the different conclusion if we take the computational cost into consideration. As mentioned in [11] Remark 3.3, SP-iteration is exactly three-step Mann iteration. Thus, Mann iteration converges faster than Noor iteration and also Ishikawa iteration under the same computational cost because Ishikawa iteration is a special case of Noor iteration.

Next, we compare the rate of convergence of D-iteration with SP-iteration and P-iteration.

Theorem 11. Let $f: E \longrightarrow E$ be a continuous nondecreasing function such that $F(f)$ is nonempty and bounded, and let $p \in F(f)$. Let $\left(h_{n}\right),\left(w_{n}\right)$, and $\left(x_{n}\right)$ be sequences defined by (4), (6), and (7), respectively, where $h_{1}=w_{1}=x_{1} \in$ E. Then, the following are satisfied.

(i) If P-iteration $\left(w_{n}\right)$ converges to $p$, then D-iteration $\left(x_{n}\right)$ converges to $p$. Moreover, $D$-iteration converges faster than P-iteration.

(ii) If SP-iteration $\left(h_{n}\right)$ converges to $p$, then $P$-iteration $\left(w_{n}\right)$ converges to $p$. Moreover, P-iteration converges faster than SP-iteration.

Proof. (i) Assume that P-iteration $\left(w_{n}\right)$ converges to $p$. Note that if $w_{1}=p$, then we are done. Assume that $w_{1} \neq p$. Consider the following two cases.

Case $1\left(w_{1}>p\right)$. If $f\left(x_{1}\right)>x_{1}$, then, by the proof of Proposition 3.6 in [10], it follows that $\left(w_{n}\right)$ does not converge to $p$ which leads to a contradiction. Thus, $f\left(x_{1}\right)<x_{1}$. Using Lemma 5(i) and Lemma 6(i), we obtain that $p \leq x_{n} \leq w_{n}$ for all $n \in \mathbb{N}$. This implies $\left|x_{n}-p\right| \leq\left|w_{n}-p\right|$ for all $n \in \mathbb{N}$. By the assumption, we have that $\left(x_{n}\right)$ converges to $p$. Furthermore, we also have that D-iteration $\left(x_{n}\right)$ converges faster than $\mathrm{P}$ iteration $\left(w_{n}\right)$.

Case $2\left(w_{1}<p\right)$. Similarly, $f\left(x_{1}\right)>x_{1}$ since if $f\left(x_{1}\right)<$ $x_{1}$, then $\left(w_{n}\right)$ does not converge to $p$ by the proof of Proposition 3.5 in [10]. Then, by Lemmas 5(ii) and 5(ii), we obtain that $w_{n} \leq x_{n} \leq p$ for all $n \in \mathbb{N}$. This implies that $\left|x_{n}-p\right| \leq\left|w_{n}-p\right|$ for all $n \in \mathbb{N}$. Therefore, D-iteration $\left(x_{n}\right)$ converges faster than P-iteration $\left(w_{n}\right)$ to $p$.

(ii) Assume that SP-iteration $\left(h_{n}\right)$ converges to $p$. By using the same proof as in (i) together with Proposition 3.5, 3.6 in [7], Lemma 5, and Lemma 6, we obtain the desired result.
TABLE 1: SP-, P-, and D-iterations for $f(x)=\left(x^{2}+2 \sqrt{x+5}\right) / 8$.

\begin{tabular}{ccccc}
\hline & SP & $\mathrm{P}$ & \multicolumn{2}{c}{ D-iteration } \\
\hline $\mathrm{n}$ & $h_{n}$ & $w_{n}$ & $x_{n}$ & $\left|f\left(x_{n}\right)-x_{n}\right|$ \\
\hline 5 & 4.089767594 & 2.761477135 & 1.948539462 & $4.20216 \mathrm{E}-01$ \\
$\ldots$ & $\ldots$ & $\ldots$ & $\ldots$ & $\ldots$ \\
15 & 1.379380405 & 1.000194745 & 1.000004283 & $3.67813 \mathrm{E}-01$ \\
16 & 1.295812521 & 1.000072757 & 1.000001234 & $3.64817 \mathrm{E}-01$ \\
17 & 1.230394331 & 1.000027194 & 1.000000357 & $3.62012 \mathrm{E}-01$ \\
18 & 1.179372155 & 1.000010168 & 1.000000103 & $3.59376 \mathrm{E}-01$ \\
19 & 1.139668491 & 1.000003803 & 1.000000030 & $3.56890 \mathrm{E}-01$ \\
20 & 1.108810300 & 1.000001423 & 1.000000009 & $3.54539 \mathrm{E}-01$ \\
\hline & & & &
\end{tabular}

TABLE 2: The rate of convergence of SP-, P-, and D-iterations for $f(x)=\left(x^{2}+2 \sqrt{x+5}\right) / 8$.

\begin{tabular}{lccc}
\hline & SP & $\mathrm{P}$ & D-iteration \\
\hline $\mathrm{n}$ & $\left|h_{n}-p\right|$ & $\left|w_{n}-p\right|$ & $\left|x_{n}-p\right|$ \\
\hline 23 & $5.1733132295 \mathrm{E}-02$ & $7.4597958699 \mathrm{E}-08$ & $2.1734436473 \mathrm{E}-10$ \\
24 & $4.0468736811 \mathrm{E}-02$ & $2.7929774493 \mathrm{E}-08$ & $6.3705707376 \mathrm{E}-11$ \\
$\ldots$ & $\ldots$ & $\ldots$ & $\ldots$ \\
29 & $1.2079291278 \mathrm{E}-02$ & $2.0582890947 \mathrm{E}-10$ & $1.4099832413 \mathrm{E}-13$ \\
30 & $9.5201332284 \mathrm{E}-03$ & $7.7109207908 \mathrm{E}-11$ & $4.1744385726 \mathrm{E}-14$ \\
31 & $7.5121079051 \mathrm{E}-03$ & $2.8889335368 \mathrm{E}-11$ & $1.2212453271 \mathrm{E}-14$ \\
32 & $5.9345143329 \mathrm{E}-03$ & $1.0824230401 \mathrm{E}-11$ & $3.5527136788 \mathrm{E}-15$ \\
\hline
\end{tabular}

It follows from Theorems 9 and 11 that $\mathrm{D}$-iteration converges faster than Mann, Ishikawa, Noor, SP-, S-, and Piterations for the class of continuous nondecreasing functions.

Remark 12. As a result from Theorem 11, we can also conclude that D-iteration converges faster than Mann iteration and P-iteration under the same computational cost. Since Siteration is a special case of P-iteration, Mann iteration converges faster than $\mathrm{S}$-iteration under the same computational cost as well. From Remark 10, we have that D-iteration is better than other iterations despite whether computational costs being considered or not.

Next, we give numerical examples of SP-, P-, and Diterations, where $\alpha_{n}=1 /\left(n^{0.2}+1\right)$ and $\beta_{n}=\gamma_{n}=1 /\left(n^{2}+1\right)$ for all $n \in \mathbb{N}$.

Example 13. Let $f:[0,8] \longrightarrow[0,8]$ be defined by $f(x)=$ $\left(x^{2}+2 \sqrt{x}+5\right) / 8$. We have that $f$ is a nondecreasing continuous function. Given the initial point $h_{1}=w_{1}=$ $x_{1}=6$. Then, SP-, P-, and D-iterations are presented in Table 1, where the fixed point $p=1$. It can be seen that $D$ iteration converges faster than other iterations as a result from Theorem 11. In addition, Table 2 shows the rate of convergence for each iteration. Notice that at least 24 steps of D-iteration must be computed to obtain an error less than $1 \times 10^{-10}$, at least 30 steps for P-iteration and more than 32 steps for SP-iteration. In fact, at least 119 steps are needed for SPiteration. 
TABLE 3: SP-, P-, and D-iterations for $f(x)=\cos (0.2 x+3)+x$.

\begin{tabular}{lcccc}
\hline & $\mathrm{SP}$ & $\mathrm{P}$ & \multicolumn{2}{c}{ D-iteration } \\
\hline $\mathrm{n}$ & $h_{n}$ & $w_{n}$ & $x_{n}$ & $\left|f\left(x_{n}\right)-x_{n}\right|$ \\
\hline 87 & -7.1308754582 & -7.1460183352 & -7.1460183659 & $1.92024 \mathrm{E}-11$ \\
88 & -7.1317558732 & -7.1460183413 & -7.1460183660 & $1.44693 \mathrm{E}-11$ \\
89 & -7.1325837416 & -7.1460183463 & -7.1460183660 & $1.09042 \mathrm{E}-11$ \\
$\ldots$ & $\ldots$ & $\ldots$ & $\ldots$ & $\ldots$ \\
113 & -7.1427309049 & -7.1460183659 & -7.1460183660 & $1.24345 \mathrm{E}-14$ \\
114 & -7.1429149653 & -7.1460183660 & -7.1460183660 & $9.76996 \mathrm{E}-15$ \\
115 & -7.1430884985 & -7.1460183660 & -7.1460183660 & $7.10543 \mathrm{E}-15$ \\
\hline
\end{tabular}

TABLE 4: The rate of convergence of SP-, P-, and D-iterations for $f(x)=\cos (0.2 x+3)+x$.

\begin{tabular}{lccc}
\hline & SP & $\mathrm{P}$ & D-iteration \\
\hline $\mathrm{n}$ & $\left|h_{n}-p\right|$ & $\left|w_{n}-p\right|$ & $\left|x_{n}-p\right|$ \\
\hline 86 & $1.6079317678 \mathrm{E}-02$ & $3.8590673768 \mathrm{E}-08$ & $1.2743317512 \mathrm{E}-10$ \\
87 & $1.5142907816 \mathrm{E}-02$ & $3.0871461831 \mathrm{E}-08$ & $9.6013863526 \mathrm{E}-11$ \\
88 & $1.4262492814 \mathrm{E}-02$ & $2.4696326761 \mathrm{E}-08$ & $7.2347461355 \mathrm{E}-11$ \\
$\ldots$ & $\ldots$ & $\ldots$ & $\ldots$ \\
112 & $3.4827043677 \mathrm{E}-03$ & $1.1655210130 \mathrm{E}-10$ & $8.3488771452 \mathrm{E}-14$ \\
113 & $3.2874611183 \mathrm{E}-03$ & $9.3240970500 \mathrm{E}-11$ & $6.3948846218 \mathrm{E}-14$ \\
114 & $3.1034007327 \mathrm{E}-03$ & $7.4591888222 \mathrm{E}-11$ & $4.7961634664 \mathrm{E}-14$ \\
$\ldots$ & $\ldots$ & $\ldots$ & $\ldots$ \\
121 & $2.0776963242 \mathrm{E}-03$ & $1.5641710149 \mathrm{E}-11$ & $7.1054273576 \mathrm{E}-15$ \\
122 & $1.9625188948 \mathrm{E}-03$ & $1.2514433934 \mathrm{E}-11$ & $6.2172489379 \mathrm{E}-15$ \\
123 & $1.8538565287 \mathrm{E}-03$ & $1.0011547147 \mathrm{E}-11$ & $6.2172489379 \mathrm{E}-15$ \\
\hline
\end{tabular}

Example 14. Let $f:[-10,5] \longrightarrow[-10,5]$ be defined by $f(x)=\cos (0.2 x+3)+x$. Then, $f$ is a nondecreasing continuous function. Given the initial point $h_{1}=w_{1}=x_{1}=$ 0 . Then, Table 3 provides SP-, P-, and D-iterations, where the fixed point $p=5 \pi / 2-15=-7.1460183660 \ldots$. Then, $D$-iteration converges faster than other iterations satisfying Theorem 11. Moreover, the rate of convergence of each iteration is shown in Table 4 . Note that at least 87 steps of D-iteration must be computed to obtain an error less than $1 \times 10^{-10}$, at least 113 steps for P-iteration, and more than 123 steps for SP-iteration. Precisely, at least 455 steps are needed for SP-iteration.

Example 15. Let $f:[0,5] \longrightarrow[0,5]$ be defined by $f(x)=$ $(0.5)^{x}$. Then, $f$ is a nonincreasing continuous function. Given the initial point, $h_{1}=w_{1}=x_{1}=4$. Then, we have SP, P-, and D-iterations as shown in Table 5, where the fixed point $p=0.6411857445 \ldots$ which is calculated by NSolve command in Mathematica to accuracy of 40 decimal places. One can see that D-iteration converges faster than other iterations. Further, the rate of convergence for each iteration is given in Table 6. As a result, at least 14 steps of D-iteration must be computed to obtain an error less than $1 \times 10^{-10}$, at least 28 steps for P-iteration, and at least 27 steps for SPiteration.
TABLE 5: SP-, P-, and D-iterations for $f(x)=(0.5)^{x}$.

\begin{tabular}{lcccc}
\hline & $\mathrm{SP}$ & $\mathrm{P}$ & \multicolumn{2}{c}{ D-iteration } \\
\hline $\mathrm{n}$ & $h_{n}$ & $w_{n}$ & $x_{n}$ & $\left|f\left(x_{n}\right)-x_{n}\right|$ \\
\hline 10 & 0.6412050446 & 0.6410282913 & 0.6411857269 & $2.54983 \mathrm{E}-08$ \\
11 & 0.6411940179 & 0.6412543436 & 0.6411857479 & $4.90076 \mathrm{E}-09$ \\
12 & 0.6411893615 & 0.6411557546 & 0.6411857438 & $9.59270 \mathrm{E}-10$ \\
13 & 0.6411873528 & 0.6411988907 & 0.6411857446 & $1.90767 \mathrm{E}-10$ \\
14 & 0.6411864703 & 0.6411799699 & 0.6411857445 & $3.84718 \mathrm{E}-11$ \\
15 & 0.6411860764 & 0.6411882852 & 0.6411857445 & $7.85594 \mathrm{E}-12$ \\
16 & 0.6411858981 & 0.6411846252 & 0.6411857445 & $1.62237 \mathrm{E}-12$ \\
17 & 0.6411858163 & 0.6411862382 & 0.6411857445 & $3.38507 \mathrm{E}-13$ \\
\hline
\end{tabular}

TABLE 6: The rate of convergence of SP-, P-, and D-iterations for $f(x)=(0.5)^{x}$.

\begin{tabular}{cccc}
\hline & SP & P & D-iteration \\
\hline $\mathrm{n}$ & $\left|h_{n}-p\right|$ & $\left|w_{n}-p\right|$ & $\left|x_{n}-p\right|$ \\
\hline 13 & $1.608284337 \mathrm{E}-06$ & $1.314622597 \mathrm{E}-05$ & $1.320704657 \mathrm{E}-10$ \\
14 & $7.258204218 \mathrm{E}-07$ & $5.774555100 \mathrm{E}-06$ & $2.663447241 \mathrm{E}-11$ \\
15 & $3.319134519 \mathrm{E}-07$ & $2.540677713 \mathrm{E}-06$ & $5.438760553 \mathrm{E}-12$ \\
16 & $1.535913483 \mathrm{E}-07$ & $1.119313535 \mathrm{E}-06$ & $1.123212634 \mathrm{E}-12$ \\
17 & $7.184125961 \mathrm{E}-08$ & $4.936533222 \mathrm{E}-07$ & $2.343680805 \mathrm{E}-13$ \\
18 & $3.393466175 \mathrm{E}-08$ & $2.179109104 \mathrm{E}-07$ & $4.940492460 \mathrm{E}-14$ \\
19 & $1.617459799 \mathrm{E}-08$ & $9.626305075 \mathrm{E}-08$ & $1.043609643 \mathrm{E}-14$ \\
20 & $7.774100030 \mathrm{E}-09$ & $4.255138120 \mathrm{E}-08$ & $2.331468352 \mathrm{E}-15$ \\
21 & $3.765638468 \mathrm{E}-09$ & $1.881918510 \mathrm{E}-08$ & $4.440892099 \mathrm{E}-16$ \\
\hline
\end{tabular}

Consequently, Example 15 suggests that this may be true for the class of nonincreasing continuous functions. This remains open. Furthermore, one can consider these iterations for larger classes of continuous functions.

\section{Data Availability}

No data were used to support this study.

\section{Conflicts of Interest}

The authors declare that there are no conflicts of interest regarding the publication of this paper.

\section{Acknowledgments}

This research is supported by Chiang Mai University, Thailand.

\section{References}

[1] W. R. Mann, "Mean value methods in iteration," Proceedings of the American Mathematical Society, vol. 4, pp. 506-510, 1953.

[2] S. Ishikawa, "Fixed points by a new iteration method," Proceedings of the American Mathematical Society, vol. 44, pp. 147-150, 1974. 
[3] B. E. Rhoades, "Comments on two fixed point iteration methods," Journal of Mathematical Analysis and Applications, vol. 56, no. 3, pp. 741-750, 1976.

[4] D. Borwein and J. Borwein, "Fixed point iterations for real functions," Journal of Mathematical Analysis and Applications, vol. 157, no. 1, pp. 112-126, 1991.

[5] M. A. Noor, "New approximation schemes for general variational inequalities," Journal of Mathematical Analysis and Applications, vol. 251, no. 1, pp. 217-229, 2000.

[6] Y. Qing and L. Qihou, "The necessary and sufficient condition for the convergence of Ishikawa iteration on an arbitrary interval," Journal of Mathematical Analysis and Applications, vol. 323, no. 2, pp. 1383-1386, 2006.

[7] W. Phuengrattana and S. Suantai, "On the rate of convergence of Mann, Ishikawa, Noor and SP-iterations for continuous functions on an arbitrary interval," Journal of Computational and Applied Mathematics, vol. 235, no. 9, pp. 3006-3014, 2011.

[8] S. Kosol, "Rate of convergence of S-iteration and Ishikawa iteration for continuous functions on closed intervals," Thai Journal of Mathematics, vol. 11, no. 3, pp. 703-709, 2013.

[9] R. P. Agarwal, D. O’Regan, and D. R. Sahu, "Iterative construction of fixed points of nearly asymptotically nonexpansive mappings," Journal of Nonlinear and Convex Analysis, vol. 8, no. 1, pp. 61-79, 2007.

[10] P. Sainuan, "Rate of convergence of P-iteration and S-iteration for continuous functions on closed intervals," Thai Journal of Mathematics, vol. 13, no. 2, pp. 449-457, 2015.

[11] Q.-L. Dong, S. He, and X. Liu, "Rate of convergence of Mann, Ishikawa and Noor iterations for continuous functions on an arbitrary interval," Journal of Inequalities and Applications, 2013:269, 9 pages, 2013. 


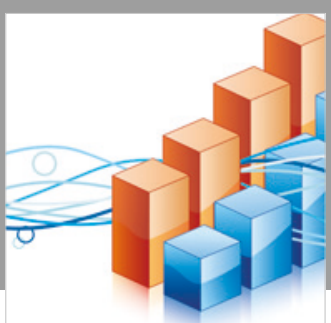

Advances in

Operations Research

\section{-n-m}
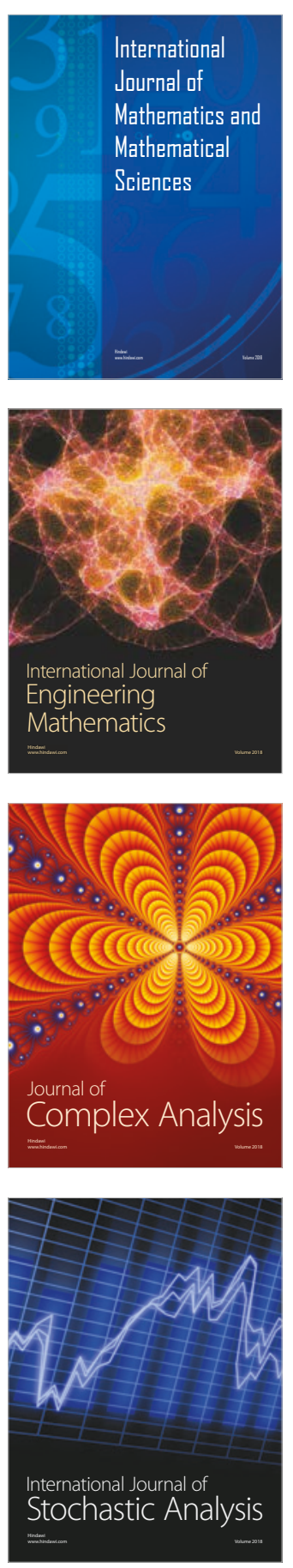
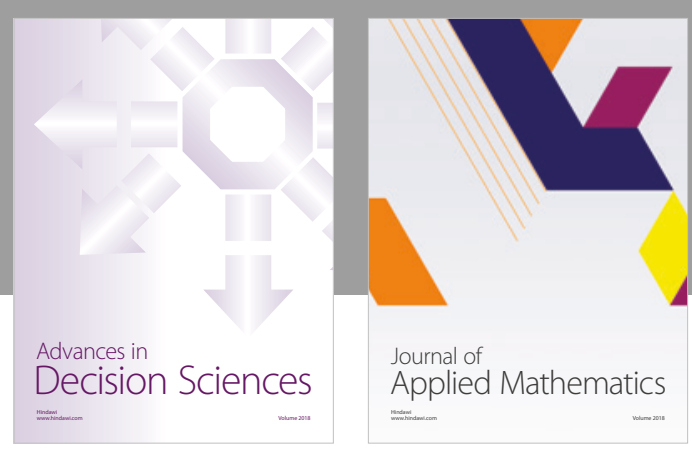

Journal of

Applied Mathematics
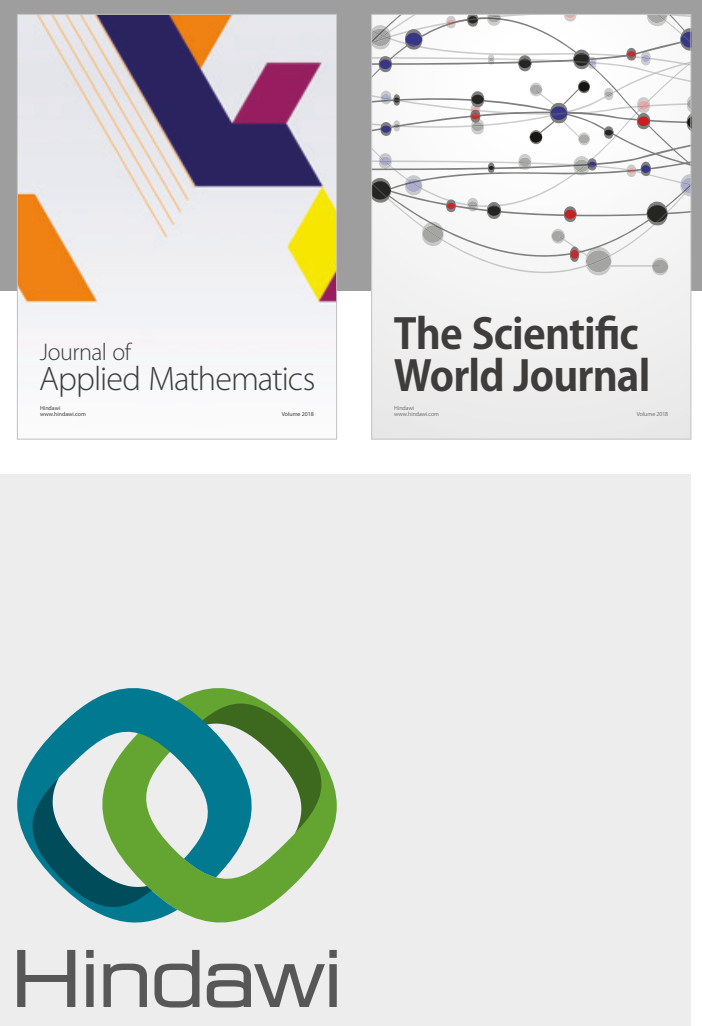

Submit your manuscripts at

www.hindawi.com

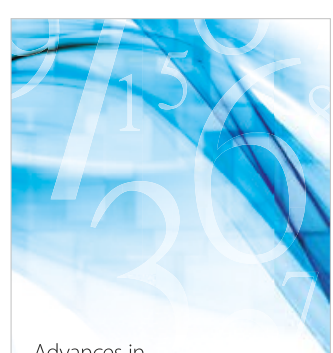

Advances in
Numerical Analysis
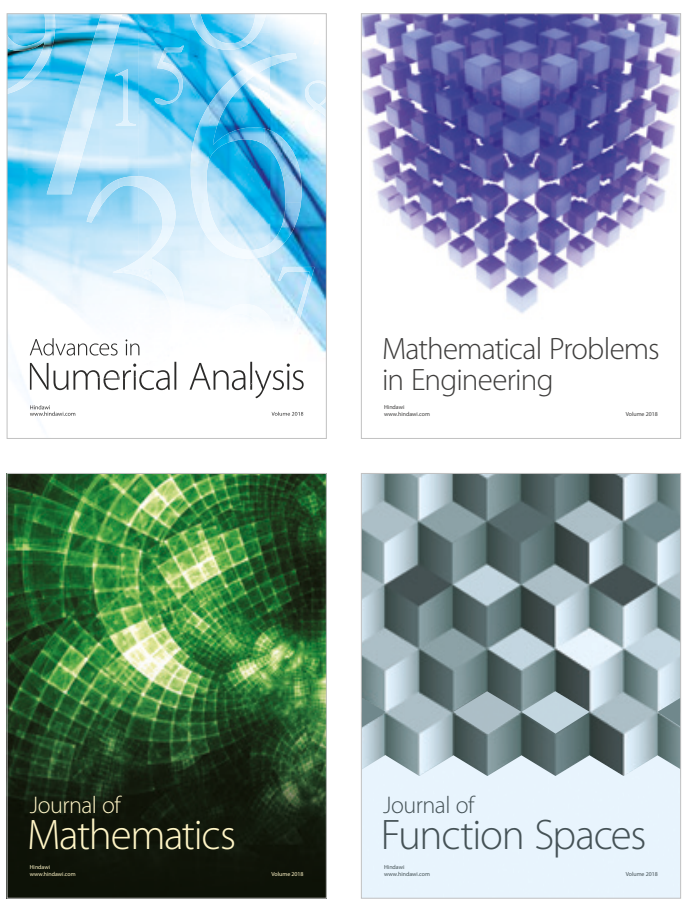

Mathematical Problems in Engineering

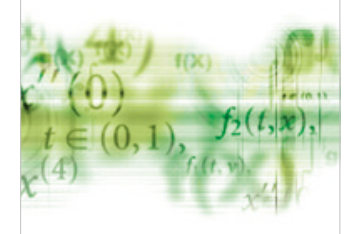

International Journal of

Differential Equations

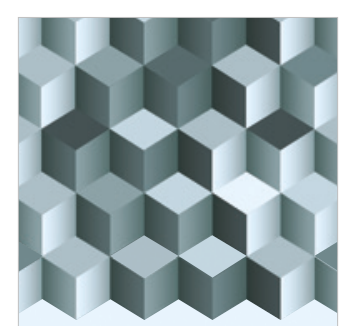

Journal of

Function Spaces

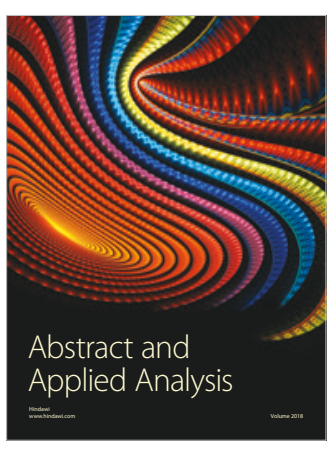

The Scientific

World Journal

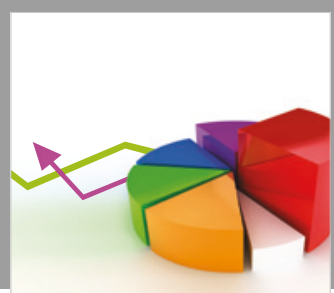

Journal of

Probability and Statistics
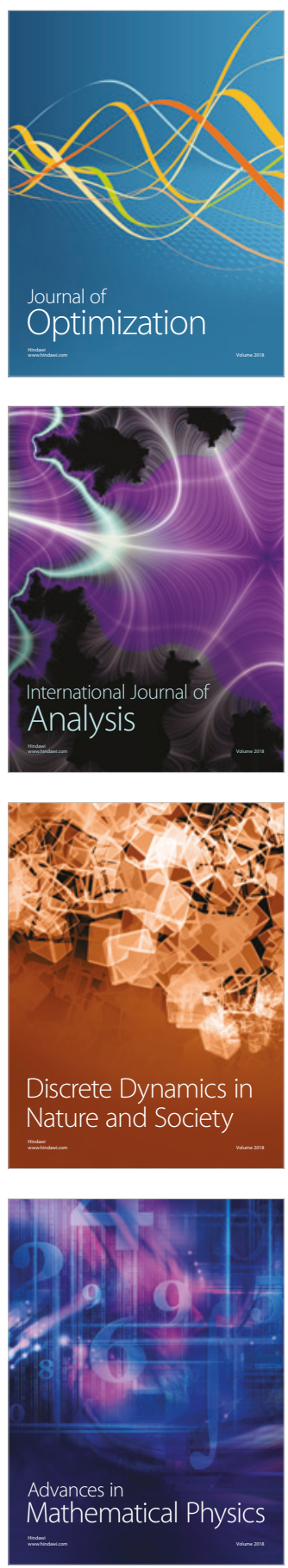